\title{
Factor Analysis Model on Impact Index for Logistics Center Location
}

\author{
Kuang Wang \\ Basic Teaching and Research Institute, Bohai University, Jinzhou, 121013, China \\ 411502202@qq.com
}

Keywords: logistics center; location; impact index; factor analysis

\begin{abstract}
Reasonable logistics center location has important role in optimizing the transport route, reducing the logistics cost, improving the operational efficiency and promoting the regional development. According to the current situation, the impact index of the logistics center location is more, this paper based on factor analysis method to study. First, build the impact indicators system of logistics center location, it consists of 12 indicators; then, according to the solving steps of factor analysis method to build mathematical model, to carry out the data calculation, and analyses the result. The 12 impact index are abstracted into 6 factors by dimensional reduction method, with less dimension integrate the data, obtained on logistics center location accurate and convenient research, the further study of the logistics center location provides a simple method.
\end{abstract}

\section{Introduction}

Principal component analysis is a multivariate statistical method to research the correlation between multiple variables, to reveal the internal structure of multiple variables through a few principal components, Export few principal components from the original variable, as far as possible to preserve the original variable information, and unrelated to each other, the principal component than the original data with a superior performance. Factor analysis is the promotion and expansion of the principal component analysis, with few factors to describe the connection between many of the indicators or factors that will more closely related to several variables classified in the same class, each class variable becomes a factor, a few factors to reflect most of the information of the original data.

Logistics center is based on a region as the main service object, from the whole region to the logistics service needs to consider, is set up in accordance with its own characteristics of region, services for regional economic and social development. Location of logistics center is a complicated systematic project, because of the large investment in the construction of logistics center, involving many factors, long service period, high risk, whether location is reasonable directly affects the smoothness, and economic benefit and operational efficiency of social logistics systems, while also have an important influence on regional planning, traffic conditions and regional environment. The preferred solution of logistics center location is to make the collection, transfer and distribution of goods through the logistics center, until benefit that the whole process of delivery to the demand node is the best. In the location planning of logistics center, have a comprehensive analysis for the impact index of the logistics center. In this paper, using factor analysis method, impact indicators will be closely grouped in a class with few factors to describe the relationship between the plurality of impact indicators, simplified analysis, for logistics center location research to provide a theoretical method.

\section{Impact Index System}

System refers to a range or similar things in a certain order and internal relations as a whole combination. Index system is an organism composed of several interrelated statistical indicators. Making a scientific, systematic and comprehensive index system is the basic work of factor analysis. Using single index or several indexes to study the logistics center location problem has certain one-sidedness and subjective. Only scientific and rational index system, it is possible to draw a scientific and impartial research conclusion. In the process of index system construction, the first to 
follow the general principles of index system construction, but also pay attention to the necessity of elements in the index system, under the circumstances without losing the overall situation, to minimize the number of system indicators, and attach much importance to the function of index system.

Logistics center is the infrastructure to achieve logistics business office, goods distribution and transport service activities, it is hardware and material carrier of logistics nodes, in order to make the logistics center embodies the organic division in function, coordination ability, spatial rational distribution, specific location should follow the following basic principles: (1) traffic guiding principles. Traffic is a key factor restricting the development of logistics, selecting the traffic conditions are good, located in the cargo occurred mainly direction and closer to the highway entrance to construct, both to avoid duplicate construction, but also to reduce the capital investment, to prevent a large number of goods back and circuitous transport; (2) urban-oriented principles. Logistics center itself is an important part of the urban infrastructure, is bound to be included in the overall urban planning. Since the logistics center involves office, storage and transportation links, covers a larger area, large quantities of goods from transport have a certain impact on the surrounding, so in general should be chosen city boundaries; (3) the terrain oriented principles. Open flat terrain, the region has scalability, reserve space for future expansion. With the development of the city, product logistics volume will increase, may put forward higher request to the scale and function of logistics park, must have enough extension space to meet the needs for further development; (4) economic adaptation principles. Logistics center should be closely related to the local economic development and industrial planning, to meet the needs of local freight volume; (5) facilities matching principle. Logistics center development is inseparable from perfect supporting facilities. Whether logistics center have sufficient energy, water and good living conditions has become an important factor in logistics center location. Structural logistics center location principle, referring to results of previous studies [1, 2], this paper constructs the index system of logistics center location as shown in Fig. 1.

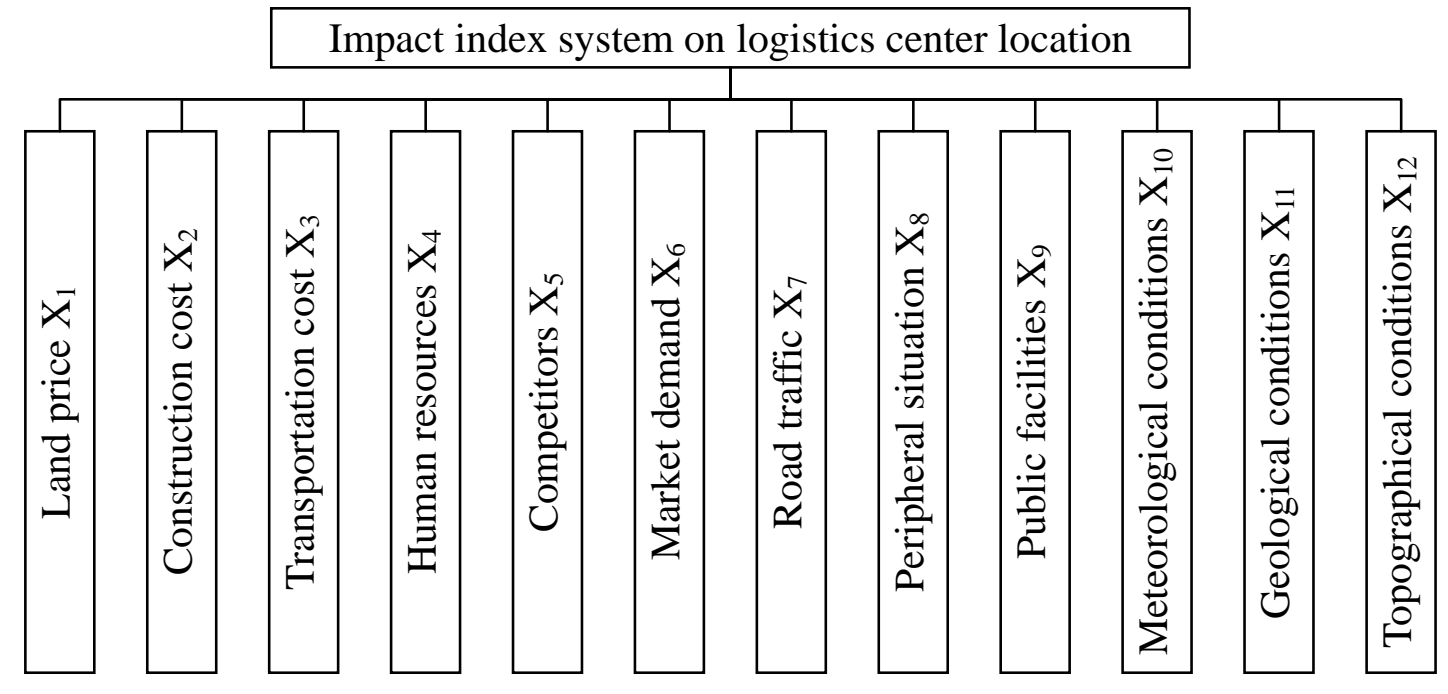

Fig. 1. Impact index system on logistics center location

\section{Factor Analysis Model}

Mathematical model is a real problem as the corresponding mathematical problem, and using mathematical concepts, methods and theories in-depth analysis, and it portrayed the practical problems from qualitative and quantitative point of view, and provide accurate data and reliable guidance to solve the problem. Factor analysis is a strict mathematical model, combined with results of previous studies [3-6], constructing the mathematical model and data calculation steps are as follows: 


\section{(1) Construct the initial matrix}

Suppose there are $m$ samples, $n$ indexes, the $j$-th index value of the $i$-th sample is $y_{i j}(i=1,2, \cdots, m \quad j=1,2, \cdots, n)$, all the sample values with the matrix is represented as:

$$
Y=\left[\begin{array}{cccc}
y_{11} & y_{12} & \cdots & y_{1 n} \\
y_{21} & y_{22} & \cdots & y_{2 n} \\
\vdots & \vdots & \cdots & \vdots \\
y_{m 1} & y_{m 2} & \cdots & y_{m n}
\end{array}\right]
$$

The initial matrix using expert scoring method, employing nine experts in the field of logistics research for 12 impact indicators were respectively scored. In order to score is more normative, the provisions of each expert for all factors of the scoring and for 120 points. Expert scoring is the original data for the calculation of the data, as shown in Table 1.

Table 1. Initial matrix

\begin{tabular}{c|c|c|c|c|c|c|c|c|c|c|c|c|c}
\hline Expert & $\mathrm{X}_{1}$ & $\mathrm{X}_{2}$ & $\mathrm{X}_{3}$ & $\mathrm{X}_{4}$ & $\mathrm{X}_{5}$ & $\mathrm{X}_{6}$ & $\mathrm{X}_{7}$ & $\mathrm{X}_{8}$ & $\mathrm{X}_{9}$ & $\mathrm{X}_{10}$ & $\mathrm{X}_{11}$ & $\mathrm{X}_{12}$ & Total \\
\hline 1 & 14 & 12 & 13 & 10 & 11 & 10 & 7 & 8 & 9 & 10 & 9 & 7 & 120 \\
\hline 2 & 10 & 7 & 11 & 9 & 14 & 6 & 9 & 9 & 10 & 16 & 8 & 11 & 120 \\
\hline 3 & 9 & 15 & 14 & 7 & 9 & 10 & 8 & 7 & 12 & 10 & 9 & 10 & 120 \\
\hline 4 & 13 & 10 & 15 & 11 & 12 & 7 & 6 & 4 & 10 & 9 & 12 & 11 & 120 \\
\hline 5 & 12 & 16 & 13 & 8 & 9 & 8 & 6 & 7 & 7 & 11 & 10 & 13 & 120 \\
\hline 6 & 11 & 12 & 13 & 8 & 15 & 6 & 9 & 8 & 6 & 11 & 12 & 9 & 120 \\
\hline 7 & 14 & 14 & 12 & 12 & 10 & 5 & 7 & 9 & 10 & 9 & 6 & 12 & 120 \\
\hline 8 & 15 & 9 & 14 & 10 & 8 & 11 & 10 & 4 & 8 & 12 & 11 & 8 & 120 \\
\hline 9 & 16 & 15 & 13 & 9 & 9 & 8 & 5 & 5 & 9 & 12 & 9 & 10 & 120 \\
\hline
\end{tabular}

\section{(2) Calculate the factor loading matrix}

Factor loading matrix is the coefficient of the factor expression of each original variable, and the influence degree of the extracted common factor to the original variable. Eigenvector matrix $U$ with p-dimensional can be decomposed into:

$$
U=\left[U_{1} U_{2} \cdots U_{k} U_{k+1} U_{k+2}\right]=\left[\begin{array}{c}
U(1) \underset{n \times k}{U} \underset{n \times(n-k)}{U(2)}
\end{array}\right]
$$

$U$ will be substituted into the factor analysis, the basic equation are:

$$
\underset{n \times m}{x}=\underset{n \times n}{U} \underset{n \times m}{f}=\left[U_{1} U_{2}\right]\left[\begin{array}{l}
f(1) \\
f(2)
\end{array}\right]=\underset{n \times k}{U(1)} \underset{k \times m}{f(1)}+\underset{n \times(n-k)(n-k) \times m}{U(2)} f(2)=U(1) f(1)+e
$$

The calculation results of initial factor loading matrix are shown in Table 2. 
Table 2. Initial factor load matrix

\begin{tabular}{|c|c|c|c|c|c|c|c|}
\hline \multirow{2}{*}{ Code } & \multirow{2}{*}{ Name } & \multicolumn{6}{|c|}{ Component } \\
\hline & & 1 & 2 & 3 & 4 & 5 & 6 \\
\hline $\mathrm{X}_{1}$ & Land price & 0.537 & -0.242 & 0.680 & 0.002 & -0.418 & 0.031 \\
\hline $\mathrm{X}_{2}$ & Construction cost & 0.303 & -0.663 & -0.549 & -0.114 & -0.303 & -0.218 \\
\hline $\mathrm{X}_{3}$ & Transportation cost & 0.870 & 0.195 & -0.155 & -0.187 & 0.380 & -0.023 \\
\hline $\mathrm{X}_{4}$ & Human resources & 0.088 & -0.330 & 0.887 & -0.031 & 0.238 & -0.097 \\
\hline $\mathrm{X}_{5}$ & Competitors & -0.658 & 0.392 & 0.110 & -0.482 & 0.232 & -0.185 \\
\hline $\mathrm{X}_{6}$ & Market demand & 0.669 & 0.350 & -0.224 & 0.557 & -0.156 & -0.049 \\
\hline $\mathrm{X}_{7}$ & Road traffic & -0.323 & 0.735 & 0.046 & 0.304 & 0.053 & -0.164 \\
\hline $\mathrm{X}_{8}$ & Peripheral situation & -0.837 & -0.224 & -0.139 & 0.098 & -0.100 & -0.441 \\
\hline $\mathrm{X}_{9}$ & Public facilities & -0.022 & -0.340 & -0.082 & 0.606 & 0.671 & 0.112 \\
\hline $\mathrm{X}_{10}$ & Meteorological conditions & -0.570 & 0.425 & 0.048 & 0.255 & -0.310 & 0.555 \\
\hline $\mathrm{X}_{11}$ & Geological conditions & 0.466 & 0.670 & -0.135 & -0.550 & 0.077 & 0.077 \\
\hline $\mathrm{X}_{12}$ & Topographical conditions & -0.303 & -0.616 & -0.222 & -0.341 & 0.141 & 0.492 \\
\hline
\end{tabular}

To make the square of coefficients $u_{i j}$ of $k$ factors in each equation close to 1 , the need for further normalization process, taking load factors $u_{i j} \sqrt{\lambda_{j}}$ as the coefficients $a_{i j}$, and even if the $i$-th variable load on the $j$-th principal factors are:

$$
a_{i j}=u_{i j} \sqrt{\lambda_{j}}
$$

So get a factor loading matrix $\mathrm{A}$ is:

$$
A=\left(a_{i j}\right)=\left[\begin{array}{cccc}
u_{11} \sqrt{\lambda_{1}} & u_{12} \sqrt{\lambda_{2}} & \cdots & u_{1 k} \sqrt{\lambda_{k}} \\
u_{21} \sqrt{\lambda_{1}} & u_{22} \sqrt{\lambda_{2}} & \cdots & u_{2 k} \sqrt{\lambda_{k}} \\
\vdots & \vdots & \cdots & \vdots \\
u_{n 1} \sqrt{\lambda_{1}} & u_{n 2} \sqrt{\lambda_{2}} & \cdots & u_{n k} \sqrt{\lambda_{k}}
\end{array}\right]
$$

The calculation results of factor loading matrix are shown in Table 3:

\begin{tabular}{|c|c|c|c|c|c|c|c|}
\hline \multirow{2}{*}{ Code } & \multirow{2}{*}{ Name } & \multicolumn{6}{|c|}{ Component } \\
\hline & & 1 & 2 & 3 & 4 & 5 & 6 \\
\hline $\mathrm{X}_{1}$ & Land price & 0.108 & -0.462 & 0.805 & 0.011 & -0.067 & -0.328 \\
\hline $\mathrm{X}_{2}$ & Construction cost & -0.185 & -0.468 & -0.277 & -0.399 & -0.684 & -0.167 \\
\hline $\mathrm{X}_{3}$ & Transportation cost & 0.879 & -0.170 & -0.011 & 0.124 & -0.408 & 0.118 \\
\hline $\mathrm{X}_{4}$ & Human resources & -0.048 & 0.164 & 0.948 & -0.032 & -0.088 & 0.184 \\
\hline $\mathrm{X}_{5}$ & Competitors & -0.110 & 0.910 & -0.113 & 0.081 & 0.170 & -0.172 \\
\hline $\mathrm{X}_{6}$ & Market demand & 0.357 & -0.692 & -0.185 & 0.555 & -0.023 & 0.090 \\
\hline $\mathrm{X}_{7}$ & Road traffic & -0.057 & 0.276 & -0.221 & 0.678 & 0.423 & 0.045 \\
\hline $\mathrm{X}_{8}$ & Peripheral situation & -0.879 & 0.385 & -0.234 & 0.032 & -0.082 & 0.020 \\
\hline $\mathrm{X}_{9}$ & Public facilities & -0.089 & -0.130 & 0.003 & -0.059 & -0.041 & 0.961 \\
\hline $\mathrm{X}_{10}$ & Meteorological conditions & -0.235 & 0.023 & -0.208 & 0.021 & 0.931 & -0.109 \\
\hline $\mathrm{X}_{11}$ & Geological conditions & 0.847 & 0.217 & -0.198 & 0.183 & -0.004 & -0.400 \\
\hline $\mathrm{X}_{12}$ & Topographical conditions & -0.133 & 0.117 & -0.106 & -0.915 & 0.023 & 0.133 \\
\hline
\end{tabular}

Table 3. Final factor load matrix 


\section{(3) The establishment of factor analysis model}

Factor analysis model adjusted is expressed as:

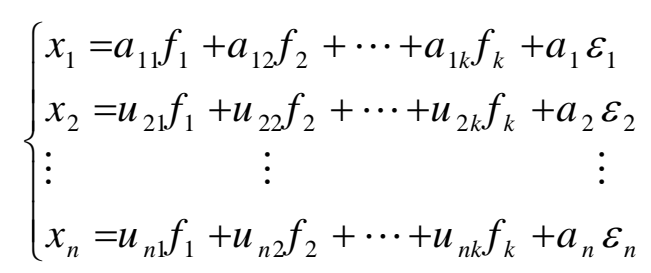

In the model, the $k$ principal factors $f_{i}(i=1,2, \cdots, k ; k<n)$ constitute $n$ mutually perpendicular coordinate relations. The size of $a_{i j}$ reflects the relative importance of the $i$-th variable on the $j$-th principal factors. The last item in the above formula is only related to the $x_{i}, \varepsilon_{i}$ called special factors.

The factor analysis model constructed according to the data of Table 3 is:

\section{(4) The results analysis}

$$
\left\{\begin{array}{l}
X_{1}=0.108 f_{1}-0.462 f_{2}+0.805 f_{3}+0.011 f_{4}-0.067 f_{5}-0.328 f_{6} \\
X_{2}=-0.185 f_{1}-0.468 f_{2}-0.277 f_{3}-0.399 f_{4}-0.684 f_{5}-0.167 f_{6} \\
X_{3}=-0.486 f_{1}+0.553 f_{2}-0.396 f_{3}+0.011 f_{4}-0.067 f_{5}-0.328 f_{6} \\
X_{4}=-0.633 f_{1}+0.624 f_{2}+0.257 f_{3}+0.011 f_{4}-0.067 f_{5}-0.328 f_{6} \\
X_{5}=0.760 f_{1}-0.070 f_{2}-0.613 f_{3}+0.011 f_{4}-0.067 f_{5}-0.328 f_{6} \\
X_{6}=0.785 f_{1}-0.402 f_{2}+0.144 f_{3}+0.011 f_{4}-0.067 f_{5}-0.328 f_{6} \\
X_{7}=0.768 f_{1}-0.039 f_{2}+0.6418 f_{3}+0.011 f_{4}-0.067 f_{5}-0.328 f_{6} \\
X_{8}=0.853 f_{1}-0.151 f_{2}+0.027 f_{3}+0.011 f_{4}-0.067 f_{5}-0.328 f_{6} \\
X_{9}=-0.089 f_{1}-0.130 f_{2}+0.003 f_{3}-0.059 f_{4}-0.041 f_{5}+0.961 f_{6} \\
X_{10}=-0.235 f_{1}+0.023 f_{2}-0.208 f_{3}+0.021 f_{4}+0.931 f_{5}-0.109 f_{6} \\
X_{11}=0.847 f_{1}+0.217 f_{2}-0.198 f_{3}+0.183 f_{4}-0.004 f_{5}-0.400 f_{6} \\
X_{12}=-0.133 f_{1}+0.117 f_{2}-0.106 f_{3}-0.915 f_{4}+0.023 f_{5}+0.133 f_{6}
\end{array}\right.
$$

On the above research factor analysis model of logistics center location impact index to draw the following conclusions: the original 12 impact indicators grouped into six factors, factor instead of the original index involved in data modeling, overcome analysis defects caused due to too many indicators in the process. A brief analysis of the 6 factors in the model is as follows:

$f_{1}$ is the most important impact factor, factor contribution rate reached $28.868 \%$, mainly reflecting the "Transportation cost, Geological conditions, Market demand" and three impact indicators.

$f_{2}$ is the second important factor, factor contribution rate reached $21.962 \%$, mainly reflecting the "Competitors, Peripheral situation, Road traffic, Geological conditions" and four impact indicators.

$f_{3}$ is the third important influence factor, factor contribution rate reached $14.4548 \%$, mainly reflecting the "Human resources, Land price" and two impact indicators.

$f_{4}$ is the fourth important influencing factors, factor contribution rate reached $12.866 \%$, mainly reflecting the "Road traffic, Market demand, Geological conditions" and three impact indicators.

$f_{5}$ is the fifth important influence factor, factor contribution rate reached $9.428 \%$, mainly reflecting the "Meteorological conditions, Road traffic, Competitors" and three impact indicators.

$f_{6}$ is the sixth important influence factor, factor contribution rate reached $7.3798 \%$, mainly reflecting the " Public facilities, Human resources, Topographical conditions" and three impact indicators. 


\section{Conclusion}

Logistics center is a comprehensive, regional, and large quantities of goods are concentrated, it plays a pivotal role in the logistics system, the upstream of center is suppliers, downstream is the supply point or demand point, plays a connecting role between the preceding and the following. Reasonable logistics center location can effectively save costs, facilitate the coordination of production and consumption, to ensure a balanced development of the logistics system. In this paper, based on factor analysis method, the 12 impact index are abstracted into 6 factors by dimensional reduction method, with less dimension integrate the data, obtained on logistics center location accurate and convenient research, the further study of the logistics center location provides a simple method.

\section{References}

[1] Congjun Rao, Mark Goh, Yong Zhao, Junjun Zheng, "Location selection of city logistics centers under sustainability," Transportation Research Part D: Transport and Environment, vol. 36, no. 5, pp. 29-44, 2015.

[2] Jacek Żak, Szymon Węgliński, "The Selection of the Logistics Center Location Based on MCDM/A Methodology," Transportation Research Procedia, vol. 3, no. 1, pp. 555-564, 2014.

[3] Joshua D. Gray, Donncha Hanna, Allison Gillen, Teresa Rushe, "A closer look at Carver and White's BIS/BAS scales: Factor analysis and age group differences," Personality and Individual Differences, vol. 95, no. 6, pp. 20-24, 2016.

[4] Jianhua Zhao, Lei Shi, "Automated learning of factor analysis with complete and incomplete data," Computational Statistics \& Data Analysis, vol. 72, no. 1, pp. 205-218, 2014.

[5] Juan Shen, Jun Wang, Er-Xin Shang, et al, "The dosage-toxicity-efficacy relationship of kansui and licorice in malignant pleural effusion rats based on factor analysis," Journal of Ethnopharmacology, vol. 186, no. 20, pp. 251-256, 2016.

[6] Vesna Spasojevic-Kalimanovska, Natasa Bogavac-Stanojevic, Dimitra Kalimanovska-Ostric,et al., "Factor analysis of risk variables associated with iron status in patients with coronary artery disease," Clinical Biochemistry, vol. 47, no. 7, pp. 564-569, 2014. 